\title{
Treatment of localized extranodal NK/T cell lymphoma, nasal type: a systematic review

\author{
Seok Jin Kim ${ }^{\dagger}$, Sang Eun Yoon ${ }^{\dagger}$ and Won Seog Kim ${ }^{*}$
}

\begin{abstract}
Extranodal natural killer/T cell lymphoma (ENKTL), nasal type, presents predominantly as a localized disease involving the nasal cavity and adjacent sites, and the treatment of localized nasal ENKTL is a major issue. However, given its rarity, there is no standard therapy based on randomized controlled trials and therefore a lack of consensus on the treatment of localized nasal ENKTL. Currently recommended treatments are based mainly on the results of phase II studies and retrospective analyses. Because the previous outcomes of anthracycline-containing chemotherapy were poor, nonanthracycline-based chemotherapy regimens, including etoposide and L-asparaginase, have been used mainly for patients with localized nasal ENKTL. Radiotherapy also has been used as a main component of treatment because it can produce a rapid response. Accordingly, the combined approach of non-anthracycline-based chemotherapy with radiotherapy is currently recommended as a first-line treatment for localized nasal ENKTL. This review summarizes the different approaches for the use of non-anthracycline-based chemotherapy with radiotherapy including concurrent, sequential, and sandwich chemoradiotherapy, which have been proposed as a first-line treatment for newly diagnosed patients with localized nasal ENKTL.
\end{abstract}

Keywords: Extranodal NK/T cell lymphoma, Chemoradiotherapy, Localized disease

\section{Background}

Extranodal natural killer/T cell lymphoma (ENKTL), nasal type, is a rare subtype of non-Hodgkin lymphoma [1]. ENKTL is characterized by the invariable infection of lymphoma cells with the Epstein-Barr virus (EBV), and the diagnostic term ENKTL originates from its immunophenotype and predominant extranodal presentation [2]. Most patients present with stage IE/IIE disease involving the nasal cavity and adjacent sites [3]. The treatment of localized nasal ENKTL is a major issue in the management of ENKTL [4]. However, given its rarity, there is a lack of consensus on the treatment of localized nasal ENKTL. The currently recommended treatments are mainly based on the results of phase II studies and retrospective analyses, and there is no standard therapy based on randomized controlled trials. In this article, we review the current recommendations for the treatment of localized ENKTL and the results of recent clinical studies relevant to the future management of localized ENKTL.

\footnotetext{
* Correspondence: wskimsmc@skku.edu

†Seok Jin Kim and Sang Eun Yoon contributed equally to this work.

Division of Hematology and Oncology, Department of Medicine, Samsung

Medical Center, Sungkyunkwan University School of Medicine, 50

Irwon-dong, Gangnam-gu, Seoul 135-710, South Korea
}

Treatment for newly diagnosed patients with localized nasal ENKTL

In contrast to other lymphomas, the treatment outcome of anthracycline-containing chemotherapies, such as $\mathrm{CHOP}$ (cyclophosphamide, doxorubicin, vincristine, and prednisone), is poor in patients with ENKTL because the tumor cells express high concentrations of the multidrug-resistant P-glycoprotein, which results in resistance to anthracycline [5-7]. Therefore, currently, non-anthracycline-based chemotherapy regimens have been suggested as a first-line treatment for localized as well as advanced ENKTL. These non-anthracycline-based regimens include ifosfamide and methotrexate, which are not affected by P-glycoprotein, and etoposide, which is effective for treating EBV-associated lymphoproliferative disorders [8, 9]. L-Asparaginase is another main drug used for non-anthracycline-based chemotherapy because tumor cells cannot synthesize $\mathrm{L}$-asparagine and die when their stores of L-asparagine are depleted by L-asparaginase [10]. L-Asparaginasebased regimens have outstanding response rates of more than $80 \%$ in patients with refractory or relapsed ENKTL $[11,12]$.

(c) The Author(s). 2018 Open Access This article is distributed under the terms of the Creative Commons Attribution 4.0 International License (http://creativecommons.org/licenses/by/4.0/), which permits unrestricted use, distribution, and reproduction in any medium, provided you give appropriate credit to the original author(s) and the source, provide a link to the Creative Commons license, and indicate if changes were made. The Creative Commons Public Domain Dedication waiver (http://creativecommons.org/publicdomain/zero/1.0/) applies to the data made available in this article, unless otherwise stated. 
Radiotherapy is also used as an initial treatment for localized ENKTL, especially in cases involving the nasal cavity and adjacent sites, because the lesion frequently presents as a small mass confined to the nasal cavity and radiotherapy can produce a rapid response. Accordingly, the upfront use of radiotherapy has been reported to improve the local control rate in patients with localized ENKTL involving the nasal cavity [13-16]. However, radiotherapy alone is currently considered as insufficient for improving survival because a substantial number of patients experience local and systemic relapse after radiotherapy alone [17-19]. As a result, the combined approach of non-anthracycline-based chemotherapy with radiotherapy has been proposed as a first-line treatment for newly diagnosed patients with localized nasal ENKTL, as discussed below.

\section{Concurrent chemoradiotherapy}

Concurrent chemoradiotherapy is based on previous findings that the upfront use of radiotherapy improves the treatment outcome of localized ENKTL. In the DeVIC (dexamethasone, etoposide, ifosfamide, and carboplatin) regimen, radiotherapy ( $50 \mathrm{~Gy}$ ) and three cycles of a twothirds dose of DeVIC chemotherapy are initiated simultaneously (Fig. 1a). This regimen was reported to have a $77 \%$ complete response $(\mathrm{CR})$ rate and $81 \%$ overall response rate [20]. The follow-up updated analysis reported that the 5 -year overall survival (OS) and progression-free survival (PFS) rates were $70 \%$ and $63 \%$, respectively, with acceptable late toxicities [21]. The benefit of this simultaneous application of radiotherapy and chemotherapy may include reduced risk of systemic progression during local therapy. However, as radiotherapy is overlapped with chemotherapy, the hematologic and non-hematologic toxicity may increase. Other regimens including ESHAP (etoposide, steroid, high-dose Ara-C and cisplatin) and DEP (dexamethasone, etoposide and cisplatin) were concurrently administered with radiotherapy, and they also showed high rates of hematologic toxicities (Table 1) [22, 23].

Another concurrent chemoradiotherapy regimen includes radiotherapy with weekly cisplatin and adjunct chemotherapy (Fig. 1b). In the first report of this regimen, concurrent

(A) Concurrent chemoradiotherapy: Simultaneous application of chemotherapy and radiotherapy

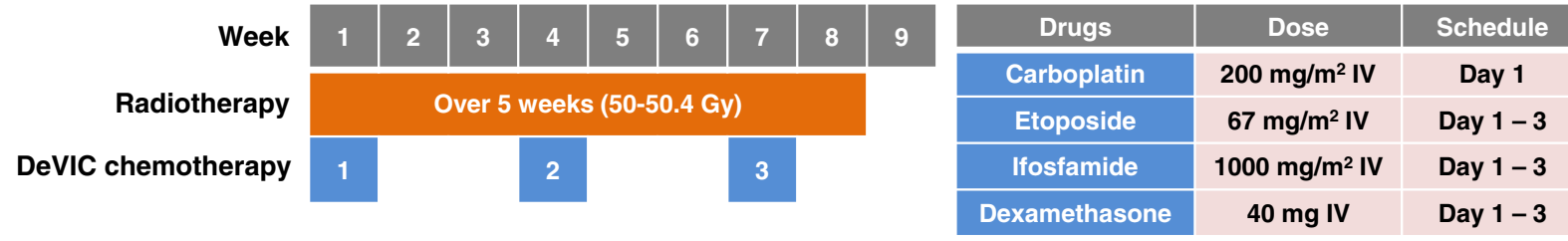

(B) Concurrent chemoradiotherapy: Concurrent chemoradiotherapy followed by chemotherapy

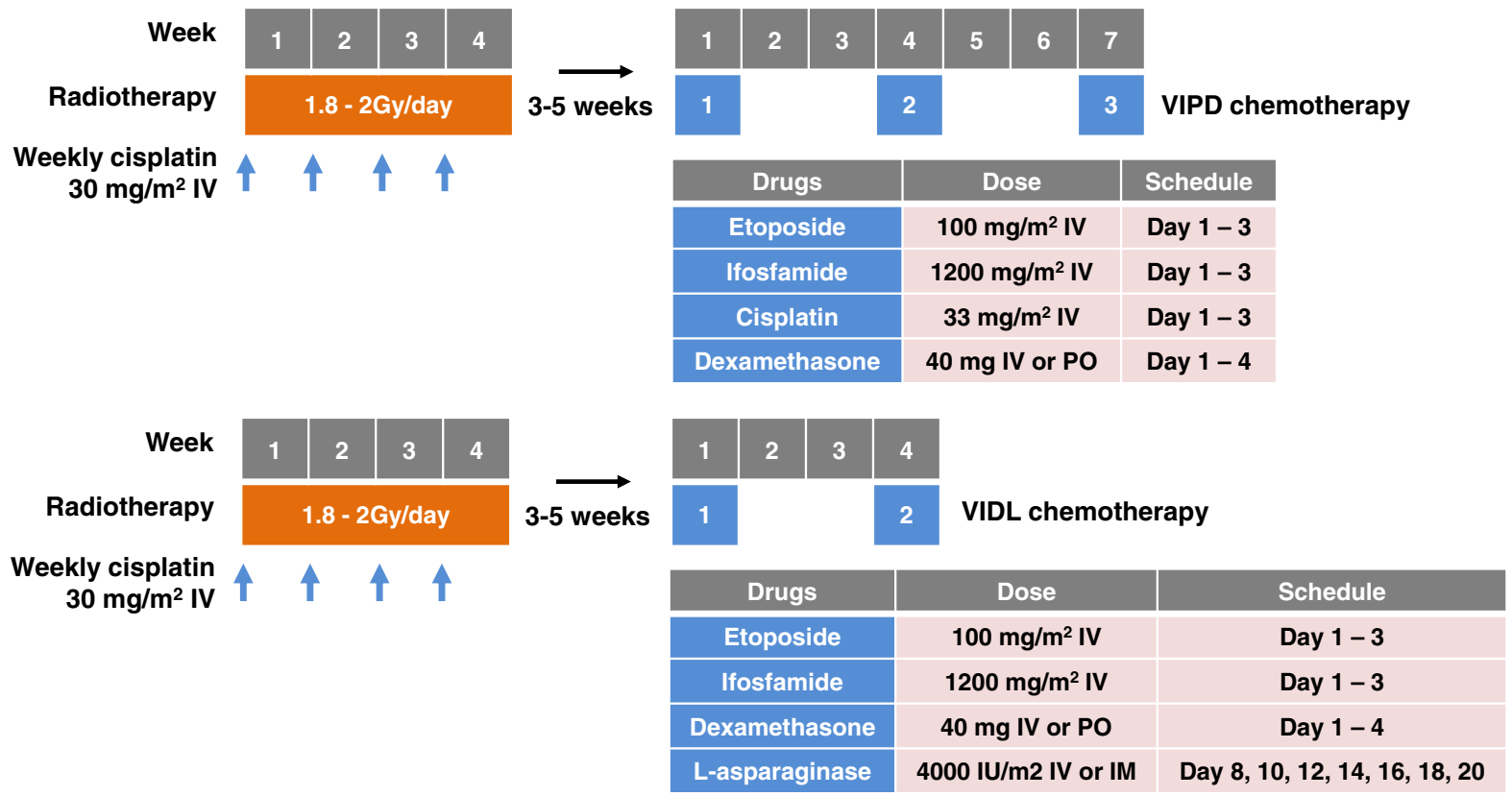

Fig. 1 a In this type of concurrent chemoradiotherapy, systemic chemotherapy is overlapped with radiotherapy. $\mathbf{b}$ Radiotherapy is combined with weekly administration of cisplatin, and adjuvant chemotherapy is followed after the completion of concurrent chemoradiotherapy 
chemoradiotherapy was followed by three cycles of VIPD (etoposide, ifosfamide, cisplatin, and dexamethasone), and an $80 \%$ CR rate and 85\% 3-year PFS rate were reported [24]. When cisplatin is used as a radiosensitizer, this approach can reduce the radiation dose by around 40 Gy. However, there is a potential risk of systemic disease progression during the period of radiotherapy. Subsequent phase II studies have tried different regimens with reduced cycle length and addition of L-asparaginase. Concurrent chemoradiotherapy followed by two cycles of VIDL (etoposide, ifosfamide, dexamethasone, and L-asparaginase) have been reported to have an $87 \%$ CR rate and 73\% 5-year PFS rate [25]. Similar outcomes have been reported for the addition of triweekly L-asparaginase to concurrent chemoradiotherapy followed by two cycles of MIDLE (methotrexate, ifosfamide, dexamethasone, $\mathrm{L}$-asparaginase, and etoposide), including an $82 \% \mathrm{CR}$ rate and 74\% 3-year PFS rate [26]. However, concurrent chemoradiotherapy followed by VIDL was less likely to cause febrile neutropenia than VIPD and MIDLE (Table 1). Similar outcomes have also been reported for other concurrent chemoradiotherapy regimens including radiotherapy with weekly cisplatin followed by 3 cycles of GDP (gemcitabine, dexamethasone, and cisplatin) in patients with localized nasal ENKTL (Table 1) [27].

\section{Sequential chemoradiotherapy}

The efficacy of SMILE (dexamethasone, methotrexate, ifosfamide, L-asparaginase, and etoposide) chemotherapy was demonstrated in a phase II study of patients with stage IV ENKTL [28]. SMILE chemotherapy is used widely as a standard of care for patients with advanced ENKTL. The Asia Lymphoma Study Group analyzed the outcome of patients with localized nasal ENKTL who received SMILE followed by radiotherapy in clinical practice. This group reported a 69\% CR rate and $90 \%$ overall response rate [29]. The sequential treatment with 2-4 cycles of SMILE and radiotherapy may be recommended as a treatment option for patients with localized nasal ENKTL (Fig. 2a) [30]. However, the hematologic toxicity was severe and common in patients receiving SMILE chemotherapy. Therefore, the SMILE regimen should be used cautiously in elderly and frail patients. Other regimens used for sequential chemoradiotherapy, including DICE-L (cisplatin, ifosfamide, etoposide, dexamethasone, and L-asparaginase), have similar outcomes (Table 1) [31].

\section{Sandwich chemoradiotherapy}

Sandwich chemoradiotherapy comprises sequential chemoradiotherapy followed by additional chemotherapy

Table 1 Chemoradiotherapy regimens for stage IE/IIE nasal extranodal NK/T cell lymphoma

\begin{tabular}{|c|c|c|c|c|c|c|}
\hline Regimen & Number & Drugs & RT & $C R$ & G3/4 neutropenia & PFS \\
\hline \multicolumn{7}{|c|}{ Concurrent chemoradiotherapy } \\
\hline \multicolumn{7}{|c|}{ Simultaneous application of chemotherapy and radiotherapy } \\
\hline DeVIC [20] & 27 & Dexamethasone, etoposide, ifosfamide, carboplatin & $50 \mathrm{~Gy}$ & $77 \%$ & $90.9 \%$ & 5 -year 67\% \\
\hline ESHAP [22] & 13 & Etoposide, steroid, Ara-C, cisplatin & $40 \mathrm{~Gy}$ & $92 \%$ & $92 \%$ & 2 -year $72 \%$ \\
\hline DEP/DVIP [23] & 33 & $\begin{array}{l}\text { Dexamethasone, etoposide, and cisplatin/dexamethasone, } \\
\text { etoposide, ifosfamide, and cisplatin }\end{array}$ & $50.4 \mathrm{~Gy}$ & $63 \%$ & $85 \%$ & 5 -year 60\% \\
\hline \multicolumn{7}{|c|}{ Weekly cisplatin with radiotherapy followed by chemotherapy } \\
\hline VIPD [24] & 30 & Etoposide, ifosfamide, cisplatin, dexamethasone & 40-52.8 Gy & $80 \%$ & $46.7 \%$ & 3 -year $85 \%$ \\
\hline VIDL [25] & 30 & Etoposide, ifosfamide, dexamethasone, L-asparaginase & 40-44 Gy & $87 \%$ & $80 \%$ & 5 -year $73 \%$ \\
\hline MIDLE [26] & 28 & $\begin{array}{l}\text { Methotrexate, ifosfamide, dexamethasone, L-asparaginase, } \\
\text { etoposide }\end{array}$ & 36-44 Gy & $82 \%$ & $91.3 \%$ & 3 -year $74 \%$ \\
\hline GDP [27] & 32 & Gemcitabine, dexamethasone and cisplatin & 56 Gy & $84.4 \%$ & $41 \%$ & 3 -year 84\% \\
\hline \multicolumn{7}{|c|}{ Sequential chemoradiotherapy } \\
\hline SMILE [29] & 17 & $\begin{array}{l}\text { Dexamethasone, methotrexate, ifosfamide, L-asparaginase, } \\
\text { etoposide }\end{array}$ & $>40 \mathrm{~Gy}$ & $69 \%$ & n.a. & n.a. \\
\hline DICE-L [31] & 33 & $\begin{array}{l}\text { Cisplatin, ifosfamide, etoposide, dexamethasone, } \\
\text { L-asparaginase }\end{array}$ & $45 \mathrm{~Gy}$ & $90.9 \%$ & n.a. & 5 -year 89\% \\
\hline \multicolumn{7}{|c|}{ Sandwich chemoradiotherapy } \\
\hline GELOX/PGEMOX [32] & 27 & $\begin{array}{l}\text { Gemcitabine, L-asparaginase, oxaliplatin/pegaspargase, } \\
\text { gemcitabine, oxaliplatin }\end{array}$ & 56 Gy & $74.1 \%$ & $33.3 \%$ & 2 -year $86 \%$ \\
\hline GELOXD/GEMOXD [35] & 167 & $\begin{array}{l}\text { Gemcitabine, L-asparaginase, oxaliplatin, } \\
\text { dexamethasone/pegaspargase, gemcitabine, oxaliplatin, } \\
\text { dexamethasone }\end{array}$ & $50 \mathrm{~Gy}$ & $88.6 \%$ & $23.4 \%^{* *}$ & 3 -year $72.8 \%$ \\
\hline
\end{tabular}

$R T$ radiotherapy, $C R$ complete response, $P F S$ progression-free survival, n.a not applicable due to lack of data 
(Fig. 2b). In a phase II study, patients with localized nasal ENKTL initially received at least two cycles of GELOX (gemcitabine, L-asparaginase, and oxaliplatin) and then received radiotherapy (56 Gy). Within 1 week after completion of radiotherapy, they received GELOX for 2-4 cycles, giving a maximum total of six cycles of GELOX. For patients who experienced hypersensitivity to L-asparaginase, pegaspargase was used instead of L-asparaginase (PGEMOX regimen: pegaspargase, gemcitabine, and oxaliplatin). This approach achieved a $74 \%$ CR rate and $96 \%$ overall response rate [32]. The updated analysis after the long-term follow-up reported an $85 \%$ 5-year OS rate and 74\% 5-year PFS rate [33]. The benefit of sandwich chemoradiotherapy may be the reduction in the intensity of chemotherapy. The main toxicities were grades 1 and 2, and no treatment-related deaths occurred during GELOX or PGEMOX [32]. Therefore, this regimen has been shown to have promising outcomes with a manageable toxicity profile in elderly patients with localized nasal ENKTL [34]. A recent retrospective analysis from three Chinese hospitals also showed a 3-year PFS of $72.8 \%$ with manageable grade 3/4 leucopenia (23.4\%) [35]. However, this approach might require a longer duration of treatment compared with concurrent or sequential chemoradiotherapy.

\section{Optimal dose and technique of radiotherapy}

As mentioned above, radiotherapy can be used in concurrent, sequential, or sandwich chemoradiotherapy for localized nasal ENKTL. However, the optimal dose and techniques of radiotherapy for the treatment of localized nasal ENKTL has not been elucidated. A previous Chinese retrospective study showed radiotherapy of $50 \mathrm{~Gy}$ could be effective for patients with low tumor burden such as stage I and normal LDH [36]. On the other hand, the safety and efficacy of concurrent chemoradiotherapy with 40 Gy were reported by a Korean retrospective study [37]. Thus, acute toxicities were tolerable during the concurrent chemoradiotherapy, and grade $\geq 3$ toxicity was found in only $4.8 \%$ of patients. Although $30 \%$ of patients experienced grade 2 nausea and mucositis during the treatment period, no case of grade $\geq 2$ late complication was observed

(A) Sequential chemoradiotherapy: Chemotherapy followed by radiotherapy

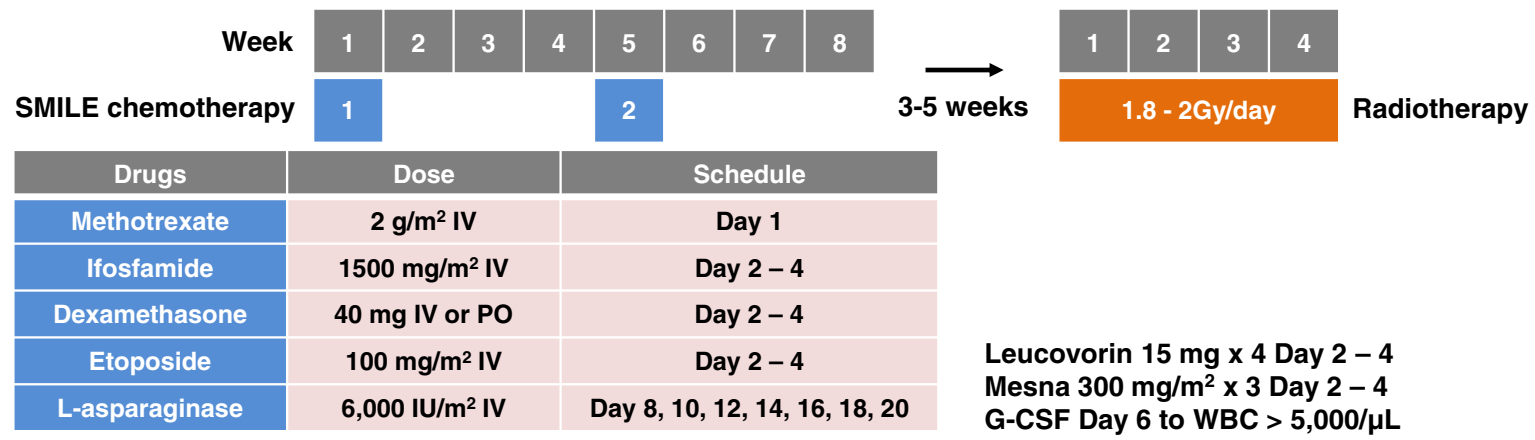

(B) Sandwich chemoradiotherapy: Chemotherapy followed by radiotherapy and chemotherapy

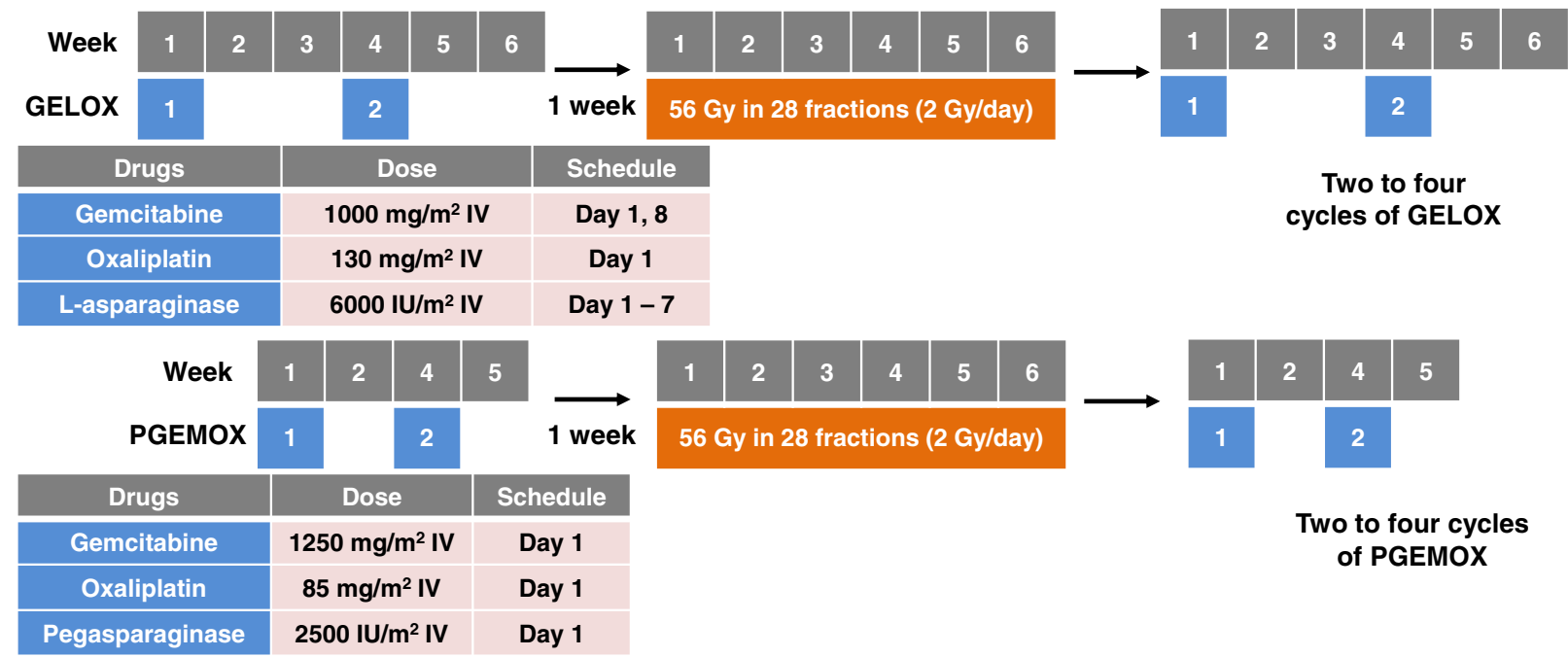

Fig. 2 a Chemotherapy is followed by radiotherapy. b Chemotherapy is followed by radiotherapy and additional cycles of chemotherapy 
with a median follow-up of 56 months [37]. Thus, for primary radiotherapy, a dose of 50 Gy could be considered whereas a radiation dose could be reduced to $40 \mathrm{~Gy}$ in concurrent chemoradiotherapy with cisplatin administration. In addition to radiation dose, as radiation technique has improved, the mode of radiotherapy also might be an important factor for treatment outcome. Although there are no controlled trials comparing 3-dimension conformal radiotherapy (3D-CRT) with intensity-modulated radiotherapy (IMRT), IMRT has significantly lower toxicities than 3D-CRT. Thus, IMRT was recommended for patients with localized nasal ENKTL by the International Lymphoma Radiation Oncology Group [38]. Recently, a retrospective analysis with 1691 Chinese patients with localized ENKTL demonstrated better 5-year OS and PFS in patients receiving IMRT $(75.9 \%$ and $67.6 \%)$ than patients with 3D-CRT $(68.9 \%$ and $58.2 \%, p<0.05)$. This survival benefit of IMRT was also significant in patients receiving combined treatment with L-asparaginase- or gemcitabine-containing chemotherapy [39]. Thus, IMRT could be an effective radiation technique for localized nasal ENKTL in terms of survival outcome and toxicity profiles.

\section{Risk-adapted treatment approach for localized nasal ENKTL}

Not all patients with localized nasal ENKTL have a better treatment outcome than do those with advanced disease because some patients can develop early relapse, which has a dismal prognosis despite the initial presentation as localized ENKTL. By contrast, other patients may have a truly localized disease with a small tumor burden. Therefore, identification of patients at high risk of treatment failure may help in developing the risk-adapted treatment approach in patients with localized nasal ENKTL. Currently, the prognostic index of natural killer lymphoma (PINK), which includes age $>60$ years, stage III or IV disease, distant lymph node involvement, and nonnasal disease, is used as a prognostic model for patients with ENKTL [40]. The PINK model is particularly useful in identifying those patients who should be treated for advanced disease. However, only a small proportion of patients with localized nasal ENKTL might belong to high risk according to the PINK model. Therefore, a modified PINK model that includes the EBV DNA titer in the blood at the time of diagnosis (PINK-E) may be more useful for identifying patients at risk of treatment failure among those with localized nasal ENKTL. The EBV DNA titer in blood has been suggested as a potential surrogate marker for disease activity because of its significant association with a high tumor burden and poor treatment outcomes [41-43]. Moreover, the presence of circulating EBV DNA at the end of treatment correlates with the risk of relapse, which suggests its potential as a marker of residual disease [44].
Recent studies comparing the outcomes of concurrent, sequential, and sandwich chemoradiotherapy have shown similar efficacy, although these were based on the results of retrospective and indirect comparisons $[45,46]$. The long-term outcomes of patients receiving concurrent chemoradiotherapy regimens including DeVIC and VIDL in Japan and Korea were also similar [47]. Therefore, all these approaches may be recommended as a first-line treatment for localized nasal ENKTL. However, the patient's age, comorbidity, and risk of systemic progression can influence the physician's choice of first-line treatment. For example, if a patient is expected to have a high risk of systemic progression such as high titer of EBV DNA, the physician might consider starting intensified chemotherapy, such as SMILE, and sequential radiotherapy.

\section{Treatment of elderly patients with localized nasal ENKTL}

The treatment strategy should be different for elderly patients, as those of other hematological malignancies because comorbidities and diminished organ function are frequent in elderly patients [48]. Indeed, a previous Chinses study analyzing elderly patients with localized nasal ENKTL receiving radiotherapy alone or a combination treatment of CHOP or CHOP-like chemotherapy with radiotherapy have shown poor 5-year OS and PFS, $42 \%$ and $40 \%$, respectively [49]. However, our single-center analysis with 51 patients ( $\geq 60$ years) demonstrated the outcome of elderly patients with localized nasal ENKTL was better than that of advanced disease [50]. In particular, concurrent chemoradiotherapy with cisplatin followed by L-asparaginase-containing chemotherapy such as VIDL was tolerable and most patients completed the planned treatment without treatment-related mortality [50]. Favorable survival outcome was also reported in elderly patients with localized ENKTL receiving GELOX/PGEMOX followed by radiotherapy [34]. Accordingly, a recent multicenter study from the China reported a favorable curability of 321 elderly patients with localized ENKTL [51]. Nonanthracycline-based chemotherapy combined with radiotherapy significantly improved 5-year PFS compared to anthracycline-based chemoradiotherapy $(71.2 \%$ vs. $44.2 \%$, $p=0.017$ ). Thus, an elderly patient might receive greater benefit from concurrent chemoradiotherapy followed by VIDL or sandwich chemoradiotherapy with GELOX/ PGEMOX (Fig. 3). In addition, only concurrent chemoradiotherapy (radiotherapy with weekly cisplatin) without adjunct chemotherapy could be tried for patients unfit for chemotherapy especially if a patient has a small mass because radiotherapy with 50 Gy alone showed a favorable survival equivalent to the general population in elderly patients with low tumor burden such as stage I, normal LDH, and absence of primary tumor invasion [51]. 


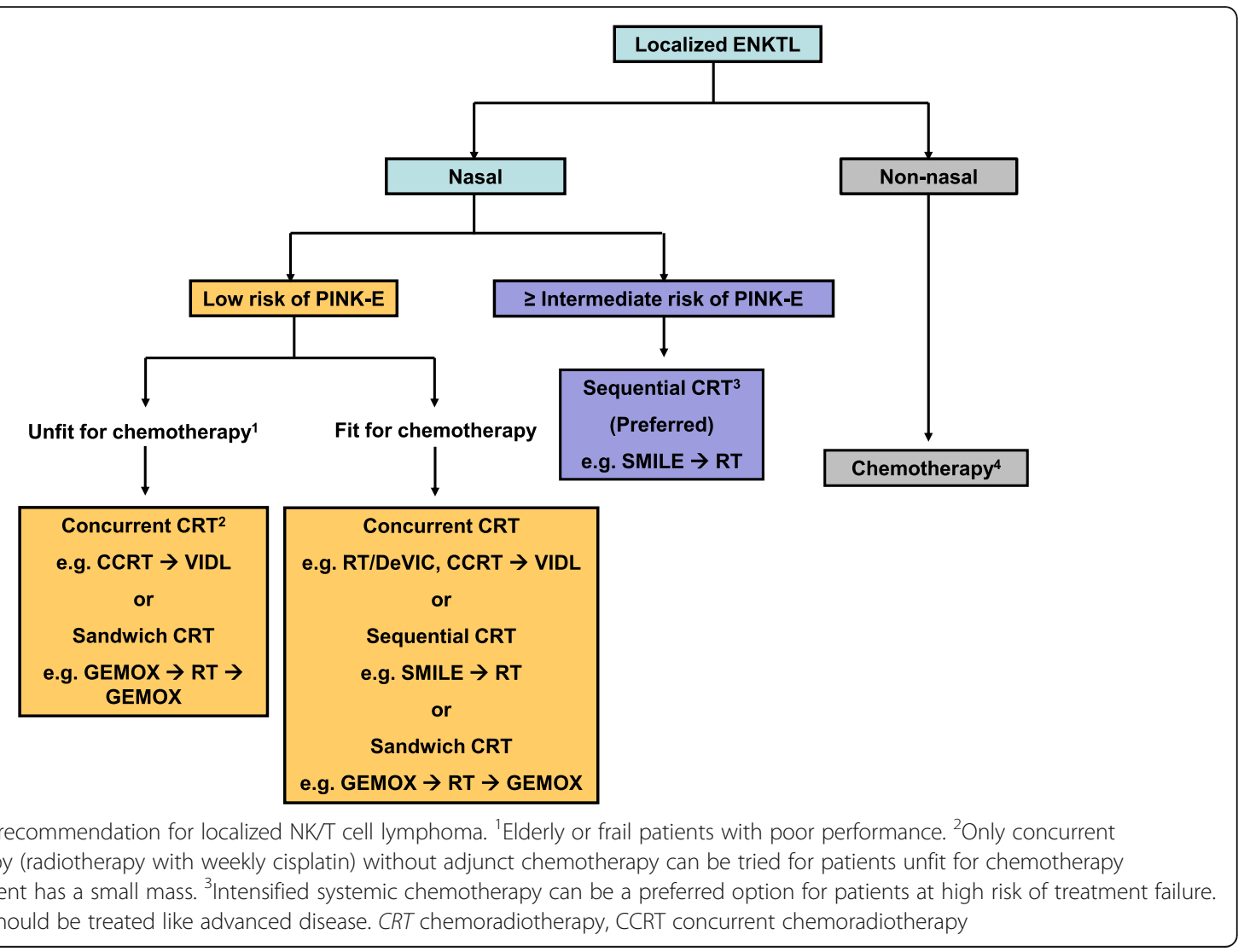

\section{CNS prophylaxis for localized nasal ENKTL}

Central nervous system (CNS) relapse is problematic because it can lead to poor prognosis in most patients with non-Hodgkin lymphoma. Because localized ENKTL frequently affects the nasal cavity and paranasal area near the CNS, ENKTL may increase the risk of CNS relapse. Our previous retrospective analysis showed that a small number of patients experienced CNS relapse $(5.76 \%, 12 / 208)$ [52]. Most patients with CNS relapse had advanced disease but not localized disease involving the nasal cavity. Therefore, CNS evaluation and prophylaxis at the time of diagnosis may not be routinely indicated for patients with localized nasal ENKTL. However, the best method to identify patients with localized nasal ENKTL at risk of CNS relapse remains unclear.

\section{Treatment of localized nonnasal ENKTL}

ENKTL can also involve other extranodal sites such as the skin, testis, intestine, and muscle [53], but it is not clear how these forms are biologically different from nasal ENKTL [54]. However, the prognosis of ENKTL involving nonnasal sites has been reported to be worse even in patients with localized disease $[55,56]$. Initial radiotherapy may not produce a favorable outcome in patients with nonnasal disease because the disease can rapidly disseminate and progress, especially when it initially presents with high blood EBV titer. Therefore, patients with localized nonnasal ENKTL should be treated with systemic chemotherapy as used in the treatment of systemic disorders.

Treatment of relapsed patients with localized nasal ENKTL Although the survival outcome of localized nasal ENKTL has improved, a substantial number of patients still relapse even after they achieve a CR [57]. Although there is no consensus on the salvage treatment for relapsed ENKTL, various treatment options might be applicable according to the pattern of relapse. For example, if patients relapse locally confined to nasal cavity without systemic symptoms and the time to relapse is longer than at least 2 years, retreatment with concurrent or sequential or sandwich chemoradiotherapy may be tried, as for newly diagnosed patients. However, if disease relapse occurs within 2 years after the completion of first-line treatment, systemic chemotherapy should be considered because the outcome of early disease relapse was found to be poor in a recent retrospective study of patients with localized nasal ENKTL receiving concurrent chemoradiotherapy [47].

\section{Conclusions}

Patients with localized nasal ENKL should be treated with a combined chemotherapy and radiotherapy treatment. 
The physician may select the treatment approach from concurrent, sequential, or sandwich chemoradiotherapy regiments according to the patient's status and risk. However, it is unknown which approach is the best for patients with localized nasal ENKTL. The risk of relapse and treatment-related toxicity remains a problematic issue for the use of the current regimens. Further studies are needed to develop more effective and tolerable treatment approaches for patients with localized nasal ENKTL.

\begin{abstract}
Abbreviations
3D-CRT : 3 dimension conformal radiotherapy; CHOP: Cyclophosphamide, doxorubicin, vincristine, prednisone; CNS: Central nervous system: CR: Complete response; DeVIC: Dexamethasone, etoposide, ifosfamide, carboplatin; DICE-L: Cisplatin, ifosfamide, etoposide, dexamethasone, L-asparaginase; EBV: Epstein-Barr virus; ENKTL: Extranodal natural killer/T cell Iymphoma; GDP: Gemcitabine, dexamethasone, and cisplatin; GELOX: Gemcitabine, L-asparaginase, oxaliplatin; IMRT: Intensity-modulated radiotherapy; MIDLE: Methotrexate, ifosfamide, dexamethasone, L-asparaginase, etoposide; OS: Overall survival; PFS: Progression-free survival; PGEMOX: Pegaspargase, gemcitabine, oxaliplatin; PINK: Prognostic index of natural killer lymphoma; SMILE: Dexamethasone, methotrexate, ifosfamide, L-asparaginase, etoposide; VIDL: Etoposide, ifosfamide, dexamethasone, L-asparaginase; VIPD: Etoposide, ifosfamide, cisplatin, dexamethasone
\end{abstract}

\section{Acknowledgements}

Not applicable

\section{Funding}

This is not applicable for this review.

\section{Availability of data and materials}

The material supporting the conclusion of this review has been included within the article.

\section{Authors' contributions}

SJK, SEY, and WSK reviewed the articles for preparing this manuscript. SJK drafted the manuscript. SJK, SEY, and WSK prepared the table and figures. All authors read and approved the final manuscript.

\section{Ethics approval and consent to participate}

This is not applicable for this review.

\section{Consent for publication}

This is not applicable for this review.

\section{Competing interests}

The authors declare that they have no competing interests.

\section{Publisher's Note}

Springer Nature remains neutral with regard to jurisdictional claims in published maps and institutional affiliations.

Received: 4 November 2018 Accepted: 12 December 2018

Published online: 20 December 2018

\section{References}

1. Harris NL, Jaffe ES, Diebold J, Flandrin G, Muller-Hermelink HK, Vardiman J, et al. World Health Organization classification of neoplastic diseases of the hematopoietic and lymphoid tissues: report of the Clinical Advisory Committee meeting-Airlie House, Virginia, November 1997. J Clin Oncol. 1999;17:3835-49.

2. Jaffe ES, Chan JK, Su IJ, Frizzera G, Mori S, Feller AC, et al. Report of the workshop on nasal and related extranodal angiocentric T/natural killer cell lymphomas. Definitions, differential diagnosis, and epidemiology. Am J Surg Pathol. 1996;20:103-11.

3. Kwong YL. Natural killer-cell malignancies: diagnosis and treatment. Leukemia. 2005;19:2186-94.
4. Oshimi K, Kawa K, Nakamura S, Suzuki R, Suzumiya J, Yamaguchi M, et al. NK-cell neoplasms in Japan. Hematology. 2005;10:237-45.

5. Yamaguchi M, Kita K, Miwa H, Nishii K, Oka K, Ohno T, et al. Frequent expression of P-glycoprotein/MDR1 by nasal T-cell lymphoma cells. Cancer. 1995;76:2351-6.

6. Kim WS, Song SY, Ahn YC, Ko YH, Baek CH, Kim DY, et al. CHOP followed by involved field radiation: is it optimal for localized nasal natural killer/T-cell Iymphoma? Ann Oncol. 2001;12:349-52.

7. Lee SH, Ahn YC, Kim WS, Ko YH, Kim K, Park K. The effect of pre-irradiation dose intense CHOP on anthracyline resistance in localized nasal NKT-cell lymphoma. Haematologica. 2006;91:427-8.

8. Chen JS, Lin KH, Lin DT, Chen RL, Jou ST, Su IJ. Longitudinal observation and outcome of nonfamilial childhood haemophagocytic syndrome receiving etoposide-containing regimens. Br J Haematol. 1998;103:756-62.

9. Uno M, Tsuchiyama J, Moriwaki A, Noguchi T, Mizoguchi K, Ogino T, et al. In vitro induction of apoptosis for nasal angiocentric natural killer cell lymphoma-derived cell line, NK-YS, by etoposide and cyclosporine a. Br J Haematol. 2001;113:1009-14.

10. Ando M, Sugimoto K, Kitoh T, Sasaki M, Mukai K, Ando J, et al. Selective apoptosis of natural killer-cell tumours by L-asparaginase. Br J Haematol. 2005;130:860-8.

11. Yong $W$, Zheng $W$, Zhu J, Zhang $Y$, Wang $X$, Xie $Y$, et al. L-Asparaginase in the treatment of refractory and relapsed extranodal NKT-cell lymphoma, nasal type. Ann Hematol. 2009;88:647-52.

12. Jaccard A, Gachard N, Coppo P, Morschhauser F, Galicier L, Ysebaert L, et al. A prospective phase II trial of an $\mathrm{L}$-asparaginase containing regimen in patients with refractory or relapsing extra nodal NKJT-cell lymphoma. Blood. 2008:112:217.

13. You JY, Chi KH, Yang MH, Chen CC, Ho CH, Chau WK, et al. Radiation therapy versus chemotherapy as initial treatment for localized nasal natural killer (NK)/T-cell lymphoma: a single institute survey in Taiwan. Ann Oncol. 2004;15:618-25.

14. Kim K, Chie EK, Kim CW, Kim IH, Park Cl. Treatment outcome of angiocentric T-cell and NK/T-cell lymphoma, nasal type: radiotherapy versus chemoradiotherapy. Jpn J Clin Oncol. 2005;35:1-5.

15. Li YX, Yao B, Jin J, Wang WH, Liu YP, Song YW, et al. Radiotherapy as primary treatment for stage IE and IIE nasal natural killer/T-cell lymphoma. J Clin Oncol. 2006;24:181-9.

16. Huang MJ, Jiang Y, Liu WP, Li ZP, Li M, Zhou L, et al. Early or up-front radiotherapy improved survival of localized extranodal NK/T-cell lymphoma, nasal-type in the upper aerodigestive tract. Int J Radiat Oncol Biol Phys. 2008;70:166-74.

17. Ribrag V, Ell Hajj M, Janot F, Girinsky T, Domenge C, Schwaab G, et al. Early locoregional high-dose radiotherapy is associated with long-term disease control in localized primary angiocentric lymphoma of the nose and nasopharynx. Leukemia. 2001;15:1123-6.

18. Cheung MM, Chan JK, Lau WH, Ngan RK, Foo WW. Early stage nasal NKKTcell lymphoma: clinical outcome, prognostic factors, and the effect of treatment modality. Int J Radiat Oncol Biol Phys. 2002;54:182-90.

19. Kim GE, Lee SW, Chang SK, Park HC, Pyo HR, Kim JH, et al. Combined chemotherapy and radiation versus radiation alone in the management of localized angiocentric lymphoma of the head and neck. Radiother Oncol. 2001;61:261-9

20. Yamaguchi M, Tobinai K, Oguchi M, Ishizuka N, Kobayashi Y, Isobe Y, et al. Phase I/II study of concurrent chemoradiotherapy for localized nasal natural killer/T-cell lymphoma: Japan Clinical Oncology Group Study JCOG0211. J Clin Oncol. 2009:27:5594-600.

21. Yamaguchi M, Tobinai K, Oguchi M, Ishizuka N, Kobayashi Y, Isobe Y, et al. Concurrent chemoradiotherapy for localized nasal natural killer/T-cell lymphoma: an updated analysis of the Japan clinical oncology group study JCOG0211. J Clin Oncol. 2012;30:4044-6.

22. Michot JM, Mazeron R, Danu A, Lazarovici J, Ghez D, Antosikova A, et al. Concurrent etoposide, steroid, high-dose Ara-C and platinum chemotherapy with radiation therapy in localised extranodal natural killer (NK)/T-cell lymphoma, nasal type. Eur J Cancer. 2015;51:2386-95.

23. Tsai HJ, Lin SF, Chen CC, Chen TY, Su WC, Hwang WL, et al. Long-term results of a phase II trial with frontline concurrent chemoradiotherapy followed by consolidation chemotherapy for localized nasal natural killer/Tcell lymphoma. Eur J Haematol. 2015;94:130-7.

24. Kim SJ, Kim K, Kim BS, Kim CY, Suh C, Huh J, et al. Phase II trial of concurrent radiation and weekly cisplatin followed by VIPD chemotherapy 
in newly diagnosed, stage IE to IIE, nasal, extranodal NK/T-cell lymphoma: Consortium for Improving Survival of Lymphoma study. J Clin Oncol. 2009; 27:6027-32.

25. Kim SJ, Yang DH, Kim JS, Kwak JY, Eom HS, Hong DS, et al. Concurrent chemoradiotherapy followed by L-asparaginase-containing chemotherapy, VIDL, for localized nasal extranodal NK/T cell Iymphoma: CISL08-01 phase I study. Ann Hematol. 2014;93:1895-901.

26. Yoon DH, Kim SJ, Jeong SH, Shin DY, Bae SH, Hong J, et al. Phase II trial of concurrent chemoradiotherapy with L-asparaginase and MIDLE chemotherapy for newly diagnosed stage I/II extranodal NK/T-cell lymphoma, nasal type (CISL-1008). Oncotarget. 2016;7:85584-91.

27. Ke QH, Zhou SQ, Du W, Liang G, Lei Y, Luo F. Concurrent IMRT and weekly cisplatin followed by GDP chemotherapy in newly diagnosed, stage IE to IIE, nasal, extranodal NK/T-cell lymphoma. Blood Cancer J. 2014;4:e267.

28. Yamaguchi M, Kwong YL, Kim WS, Maeda Y, Hashimoto C, Suh C, et al. Phase II study of SMILE chemotherapy for newly diagnosed stage IV, relapsed, or refractory extranodal natural killer (NK)/T-cell lymphoma, nasal type: the NK-Cell Tumor Study Group study. J Clin Oncol. 2011;29:4410-6.

29. Kwong YL, Kim WS, Lim ST, Kim SJ, Tang T, Tse E, et al. SMILE for natural killer/T-cell lymphoma: analysis of safety and efficacy from the Asia Lymphoma Study Group. Blood. 2012;120:2973-80.

30. Tse E, Kwong YL. How I treat NK/T-cell lymphomas. Blood. 2013;121:4997-5005.

31. Dong LH, Zhang LJ, Wang WJ, Lei W, Sun X, Du JW, et al. Sequential DICE combined with l-asparaginase chemotherapy followed by involved field radiation in newly diagnosed, stage IE to $I I E$, nasal and extranodal NK/T-cell lymphoma. Leuk Lymphoma. 2016;57:1600-6.

32. Wang L, Wang ZH, Chen XQ, Li YJ, Wang KF, Xia YF, et al. First-line combination of gemcitabine, oxaliplatin, and L-asparaginase (GELOX) followed by involved-field radiation therapy for patients with stage IE/IIE extranodal natural killer/T-cell lymphoma. Cancer. 2013;119:348-55.

33. Wang $L$, Wang ZH, Chen XQ, Wang KF, Huang HQ, Xia ZJ. First-line combination of GELOX followed by radiation therapy for patients with stage IE/IIE ENKTL: an updated analysis with long-term follow-up. Oncol Lett. 2015;10:1036-40.

34. Bi XW, Xia Y, Zhang WW, Sun P, Liu PP, Wang Y, et al. Radiotherapy and PGEMOX/GELOX regimen improved prognosis in elderly patients with earlystage extranodal NK/T-cell lymphoma. Ann Hematol. 2015;94:1525-33.

35. Li JW, Li YJ, Zhong MZ, Liu XL, Li J, Li KL, et al. Efficacy and tolerance of GELOXD/P-GEMOXD in newly diagnosed nasal-type extranodal NK/T-cell lymphoma: a multicenter retrospective study. Eur J Haematol. 2018;100:247-56.

36. Yang Y, Zhu Y, Cao JZ, Zhang YJ, Xu LM, Yuan ZY, et al. Risk-adapted therapy for early-stage extranodal nasal-type NK/T-cell lymphoma: analysis from a multicenter study. Blood. 2015;126:1424-32 quiz 517.

37. Oh D, Ahn YC, Kim SJ, Kim WS, Ko YH. Concurrent chemoradiation therapy followed by consolidation chemotherapy for localized extranodal natural killer/T-cell lymphoma, nasal type. Int J Radiat Oncol Biol Phys. 2015;93:677-83.

38. Yahalom J, Illidge T, Specht L, Hoppe RT, Li YX, Tsang R, et al. Modern radiation therapy for extranodal lymphomas: field and dose guidelines from the International Lymphoma Radiation Oncology Group. Int J Radiat Oncol Biol Phys. 2015;92:11-31

39. Wu T, Yang Y, Zhu SY, Shi M, Su H, Wang Y, et al. Risk-adapted surviva benefit of IMRT in early-stage NKTCL: a multicenter study from the China Lymphoma Collaborative Group. Blood Adv. 2018;2:2369-77.

40. Kim SJ, Yoon DH, Jaccard A, Chng WJ, Lim ST, Hong H, et al. A prognostic index for natural killer cell lymphoma after non-anthracycline-based treatment: a multicentre, retrospective analysis. Lancet Oncol. 2016;17:389-400.

41. Au WY, Pang A, Choy C, Chim CS, Kwong YL. Quantification of circulating Epstein-Barr virus (EBV) DNA in the diagnosis and monitoring of natural killer cell and EBV-positive lymphomas in immunocompetent patients. Blood. 2004;104:243-9.

42. Kim HS, Kim KH, Kim KH, Chang MH, Ji SH, Lim DH, Kim K, et al. Whole blood Epstein-Barr virus DNA load as a diagnostic and prognostic surrogate: extranodal natural killer/T-cell lymphoma. Leuk Lymphoma. 2009:50(5):757-63.

43. Kwong YL, Pang AW, Leung AY, Chim CS, Tse E. Quantification of circulating Epstein-Barr virus DNA in NK/T-cell lymphoma treated with the SMILE protocol: diagnostic and prognostic significance. Leukemia. 2014;28:865-70.

44. Kim SJ, Choi JY, Hyun SH, Ki CS, Oh D, Ahn YC, et al. Risk stratification on the basis of Deauville score on PET-CT and the presence of Epstein-Barr virus DNA after completion of primary treatment for extranodal natural killer/T-cell lymphoma, nasal type: a multicentre, retrospective analysis. Lancet Haematol. 2015;2:e66-74.
45. Li J, Li Y, Zhong M, Liu W, Liu X, Li J, et al. A multicenter retrospective comparison of sequential versus sandwich chemoradiotherapy for stage IE-IIE extranodal natural killer/T-cell lymphoma. Nasal Type J Cancer. 2018;9:1598-606.

46. Kwong YL, Kim SJ, Tse E, Oh SY, Kwak JY, Eom HS, et al. Sequential chemotherapy/radiotherapy was comparable with concurrent chemoradiotherapy for stage I/II NK/T-cell lymphoma. Ann Oncol. 2018;29:256-63.

47. Yamaguchi M, Suzuki R, Kim SJ, Ko YH, Oguchi M, Asano N, et al. Early disease progression in patients with localized natural killer/T-cell lymphoma treated with concurrent chemoradiotherapy. Cancer Sci. 2018;109:2056-62.

48. Smith A, Crouch S, Howell D, Burton C, Patmore R, Roman E. Impact of age and socioeconomic status on treatment and survival from aggressive Iymphoma: a UK population-based study of diffuse large B-cell lymphoma. Cancer Epidemiol. 2015;39:1103-12.

49. Wang ZY, Li YX, Wang H, Wang WH, Jin J, Liu YP, et al. Unfavorable prognosis of elderly patients with early-stage extranodal nasal-type NK/Tcell lymphoma. Ann Oncol. 2011;22:390-6.

50. Kim SM, Park S, Oh DR, Ahn YC, Ko YH, Kim SJ, et al. Extra-nodal natural killer/T cell lymphoma in elderly patients: the impact of aging on clinical outcomes and treatment tolerability. Ann Hematol. 2016;95:581-91.

51. Chen B, Zhu SY, Shi M, Su H, Wang Y, He X, et al. Risk-dependent curability of radiotherapy for elderly patients with early-stage extranodal nasal-type NK/T-cell lymphoma: a multicenter study from the China Lymphoma Collaborative Group (CLCG). Cancer Med. 2018.

52. Kim SJ, Oh SY, Hong JY, Chang MH, Lee DH, Huh J, et al. When do we need central nervous system prophylaxis in patients with extranodal NKT-cell lymphoma, nasal type? Ann Oncol. 2009;21:1058-63.

53. Chan JK, Sin VC, Wong KF, Ng CS, Tsang WY, Chan CH, et al. Nonnasal lymphoma expressing the natural killer cell marker CD56: a clinicopathologic study of 49 cases of an uncommon aggressive neoplasm. Blood. 1997;89:4501-13.

54. Lim ST, Hee SW, Quek R, Lim LC, Yap SP, Loong EL, et al. Comparative analysis of extra-nodal NK/T-cell lymphoma and peripheral T-cell lymphoma: significant differences in clinical characteristics and prognosis. Eur J Haematol. 2008:80:55-60

55. Au WY, Weisenburger DD, Intragumtornchai T, Nakamura S, Kim WS, Sng I, et al. Clinical differences between nasal and extranasal natural killer/T-cell Iymphoma: a study of 136 cases from the International Peripheral T-Cell Lymphoma Project. Blood. 2009;113:3931-7.

56. Kim TM, Lee SY, Jeon YK, Ryoo BY, Cho GJ, Hong YS, et al. Clinical heterogeneity of extranodal NKT-cell lymphoma, nasal type: a national survey of the Korean Cancer Study Group. Ann Oncol. 2008;19:1477-84.

57. Yamaguchi M, Suzuki R, Oguchi M, Asano N, Amaki J, Akiba T, et al. Treatments and outcomes of patients with extranodal natural killer/T-cell lymphoma diagnosed between 2000 and 2013: a Cooperative Study in Japan. J Clin Oncol. 2017;35:32-9.

Ready to submit your research? Choose BMC and benefit from

- fast, convenient online submission

- thorough peer review by experienced researchers in your field

- rapid publication on acceptance

- support for research data, including large and complex data types

- gold Open Access which fosters wider collaboration and increased citations

- maximum visibility for your research: over $100 \mathrm{M}$ website views per year

At BMC, research is always in progress.

Learn more biomedcentral.com/submission 